\title{
RECENT TRENDS IN MORTALITY FROM LUNG CANCER AND BRONCHITIS IN URBAN AND RURAL AREAS IN SCOTLAND
}

\author{
EILEEN C. CROFTON, B.M., B.Ch. \\ Research Assistant \\ Department of Respiratory Diseases, University of Edinburgh
}

The steady and persistent rise in mortality from lung cancer has been a marked feature of the national statistics for many years. More recently the increasing number of male deaths attributed to bronchitis has given rise to concern. The association of both diseases with cigarette smoking has been established beyond any reasonable doubt in numerous studies in many parts of the world. In Britain, surveys of cigarette smoking have, in recent years, been undertaken by the Tobacco Research Council (Todd, 1966). Waller (1959) has suggested that cigarette smoking occurred earlier in London than in the rural areas of England and Wales and predicted, on the basis of this hypothesis, that the death rates for lung cancer in rural areas would, in time, approach the rates in London and other large towns. Buck and Brown (1964) examined standardized mortality rates and standard mortality ratios in men in urban and rural areas in England and Wales from 1952 to 1961. They found that over this period the rates rose steadily in parallel, and concluded that their data did not support Waller's hypothesis. They did not, however, take into account the proportionate scale of these changes, nor did they examine different age groups. It has been noted recently (Smith, 1964: Springett, 1966) that whereas the total lung cancer mortality has been increasing steadily, the rise in the younger males has been slowing down, and at some ages has become stationary.

In view of these findings it was thought to be of interest to examine the age-specific death rates in Scottish males in urban and rural areas separately. Such a study might uncover trends that remained concealed when all ages were combined. It was thought valuable also to examine mortality from bronchitis in the same way in view of its aetiological association with smoking.

\section{METHOD}

The Registrar-General for Scotland (1950-65) seports annually the number of deaths occurring in different aggregate areas in Scotland. These areas are classified as (1) conurbation (Central Clydeside), (2) four cities, (3) large burghs (20), (4) small burghs (174), and (5) landward, i.e., 'rural' areas. The conurbation contains within its boundaries Glasgow City and some areas out of each of the other categories. It is not, therefore, a very homogeneous area. There is some overlap in population size between towns classified as 'large' and towns classified as 'small' burghs, and the latter vary enormously in size, from 327 to 21,102 inhabitants (1961 census). It has, accordingly, been thought more valuable to confine the analysis in this paper to differences in mortality between the cities (population over 100,000) and the landward areas. This also has the advantage of affording a comparison between the most urban and highly populated areas, and the least urban and least populated areas.

This paper is concerned only with male mortality. Female deaths in both disease categories run at a very much lower level, and the number of deaths in each age group is too small to permit a satisfactory analysis.

Male death rates standardized for age were calculated for respiratory neoplasm (I.S.D. 162, 163) and bronchitis (I.S.D. 500-502) for the years 1951 to 1965 inclusive. The standard population used was that found in the 1951 census for Scotland and England and Wales combined. The populations at risk (males only) were 893,630 in the cities and 754,948 in the landward areas (1961 census).

Male death rates in the same disease categories were also calculated for the age groups 45-54, 55-64, 65-74 and 75 years and over. Populations at risk in each age group were based on the 1951 and 1961 censuses and calculated for each year by applying the 1951 to 1961 intercensal change to the 1961 population, assuming that the annual rate of change was a uniform one. The populations at risk varied in size from 11,046 (75 and over in the cities) to 80,922 (45-54 in landward areas). 


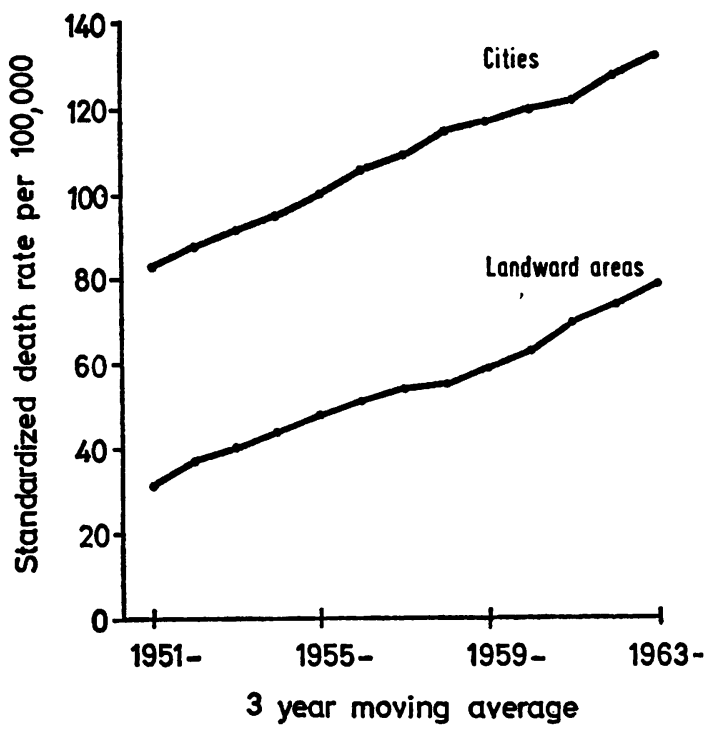

Fig. 1.-Male lung cancer mortality in cities and landward areas in Scotland, 1951-65.

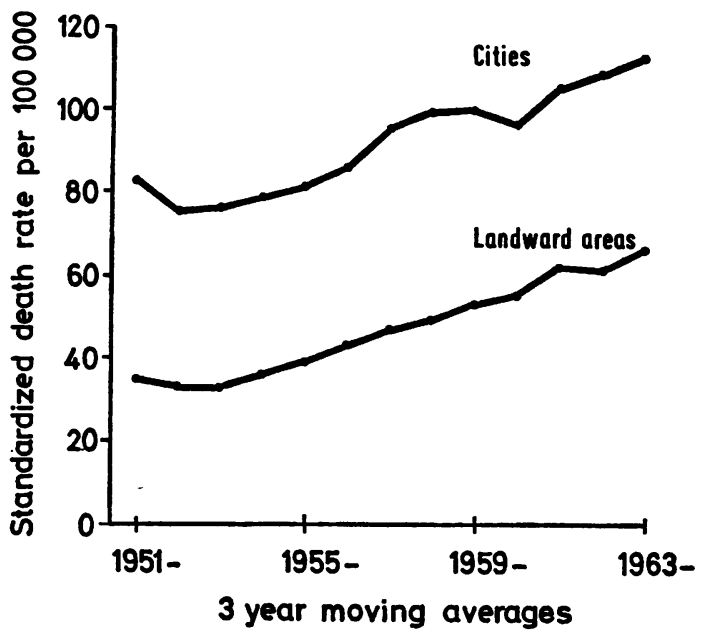

FIG. 2.-Male bronchitis mortality in cities and landward areas in Scotland, 1951-65.

\section{RESULTS}

Figures 1 and 2 show the standardized death rates for lung cancer and bronchitis in males in the cities and landward areas from 1951 to 1965 . The rates are shown in three-year moving averages, a method which eliminates some of the annual variations which may occur by chance when the number of deaths is relatively small or, in the case of bronchitis, as a result of climatic variations and influenza epidemics. There is a steady rise in both diseases.
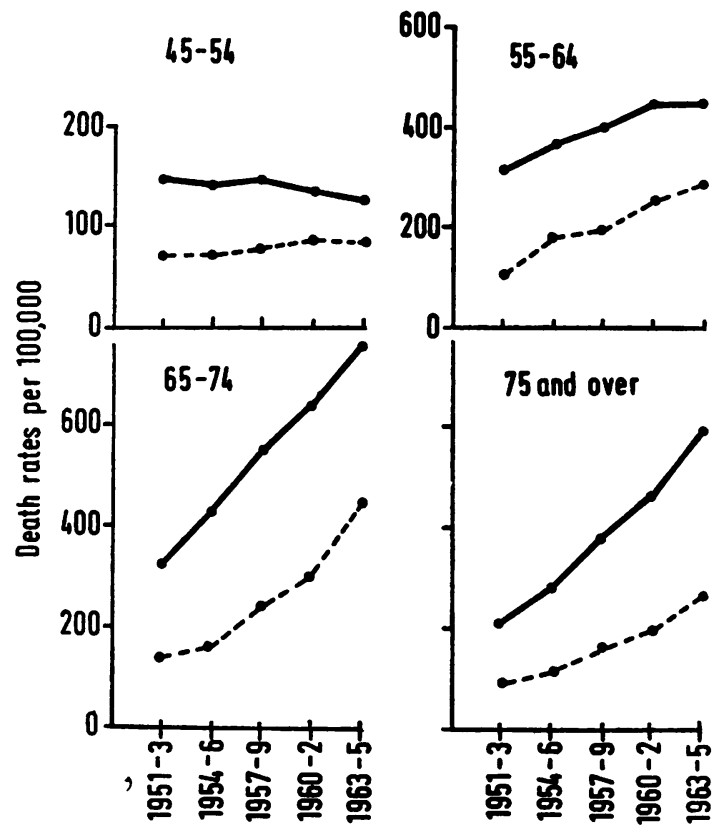

...-- Landward areas

FiG. 3.- Male lung cancer mortality by age in cities and landward areas in Scotland (note differences in scale).

The increase is, of course, proportionately greater in the landward areas (for lung cancer $155 \%$ compared to $59 \%$ in the cities, and for bronchitis a rise of $89 \%$ compared to $46 \%$ in the cities).

Figure 3 shows the male age-specific death rate for lung cancer in three-year averages (not moving). The highest death rate occurred in the 65-74 age group in each three-year average except for 1954-56 when the highest death rate in the landward areas occurred in the 55-64 age group. In the 45-54 age group the rate in the cities fell, while in the landward areas it rose, at least until 1960-62. At age 55-64 the rate in the cities did not rise in the last three-year period, while the rate in the landward areas rose as steeply as before. At older ages of death the rates in both areas rose over the whole period.

Figure 4 shows the male age-specific rates for bronchitis. The highest death rates are in the age group dying at 75 and over, but it must be remembered that diagnosis of the cause of death at this age is less accurate than at other ages, as many interrelated factors may be concerned, all contributing in different degrees to the final outcome. As with lung cancer, there is a fall in the rates in the 45-54 age group in the cities, and a slight rise in the landward areas. The 55-64 and 65-74 age groups show a rise in both areas. 


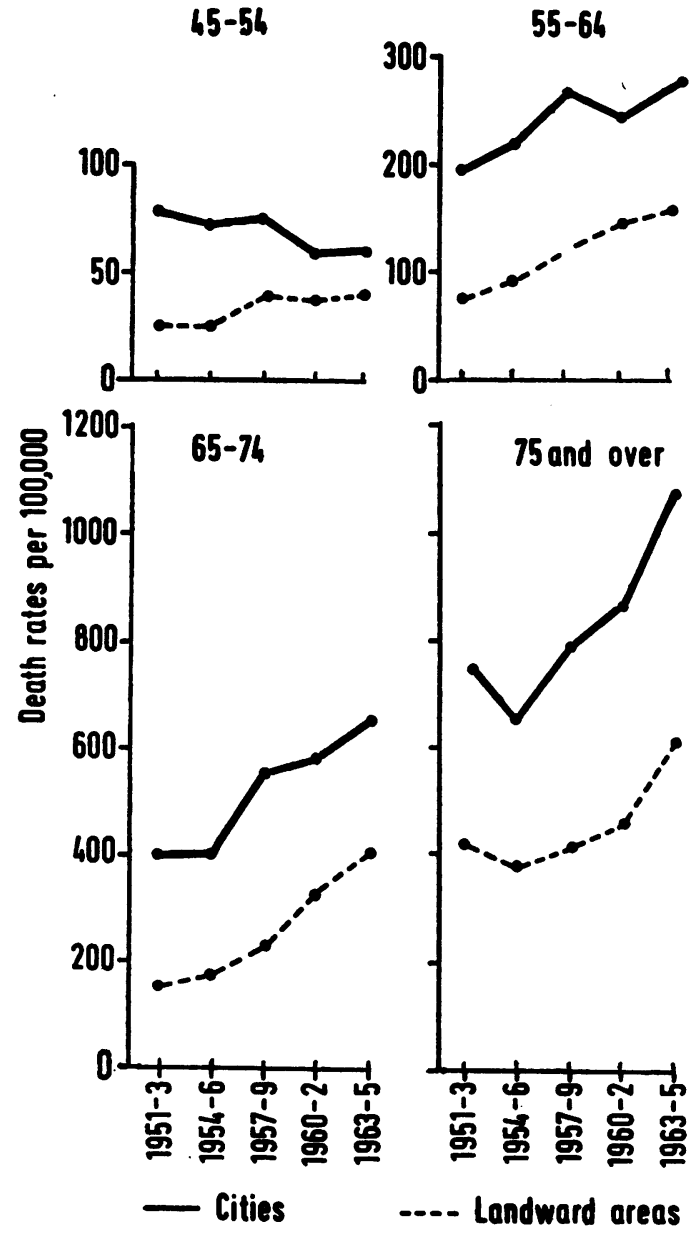

Fig. 4.-Male bronchitis mortality by age in cities and landward areas in Scotland (note differences in scale).
TABLE I

PERCENTAGE CHANGE IN MALE AGE-SPECIFIC DEATH RATES, 1951-53 AND 1963-65

\begin{tabular}{|c|c|c|c|c|}
\hline \multirow{2}{*}{ Disease and Area } & \multicolumn{4}{|c|}{ Age Group (yr) } \\
\hline & $45-54$ & $55-64$ & $65-74$ & 75 and over \\
\hline $\begin{array}{l}\text { Lung cancer } \\
\text { Cities } \\
\text { Landward areas }\end{array}$ & $\begin{array}{r}-15.0 \\
+21.0\end{array}$ & $\begin{array}{r}+45.6 \\
+180.0\end{array}$ & $\begin{array}{r}+132.0 \\
+225.8\end{array}$ & $\begin{array}{r}+175.3 \\
+200.7\end{array}$ \\
\hline $\begin{array}{l}\text { Bronchitis } \\
\text { Cities } \\
\text { Landward areas }\end{array}$ & $\begin{array}{r}-22.7 \\
+64.3\end{array}$ & $\begin{array}{r}+41.5 \\
+109.9\end{array}$ & $\begin{array}{r}+61.9 \\
+159.6\end{array}$ & $\begin{array}{l}+45.0 \\
+44.3\end{array}$ \\
\hline
\end{tabular}

Table I shows the percentage change in the male age-specific death rates between 1951-53 and 196365 . The increase in the $45-54$ age group in the landward areas and the decrease in the cities have already been commented on. This difference is seen in both diseases, but it is particularly marked in the case of bronchitis. With the exception of those dying at the age of 75 and over from bronchitis there is a greater proportionate increase in the landward areas.

Table II shows the ratio of the male death rates in the cities to those in landward areas for all ages (rates standardized for age) and for individual age groups. With the exception of those dying at 75 and over from bronchitis there is a fall in the ratio between 1951-53 and 1963-65. In most instances this fall is consistent. In the case of lung cancer the greatest reduction $(48 \%)$ is seen in the 55-64 age group. The $45-54$ age group shows a $30 \%$ reduction and the $65-74$ age group $29 \%$. There is little change $(9 \%)$ in those dying at 75 and over. In 1951-53 the difference was greatest in the 55-64 age group. In 1954-56 the greatest difference between urban and rural rates had shifted to the 65-74 age group and thereafter to those dying at 75 and over.

In bronchitis, on the other hand, the biggest change in the ratio is seen in the youngest age group

TABLE II

RATIO OF MALE DEATH RATES IN CITIES TO THOSE IN LANDWARD AREAS IN SCOTLAND BETWEEN 1951 AND 1965

\begin{tabular}{|c|c|c|c|c|c|c|}
\hline Cause of Death and Age Group & $1951-53$ & $1954-56$ & $1957-59$ & $1960-62$ & $1963-65$ & $\begin{array}{c}\text { Change between } \\
1951-53 \text { and 1963-65 } \\
(\%)\end{array}$ \\
\hline $\begin{array}{l}\text { Lung cancer } \\
\text { All ages (rates standardized) }\end{array}$ & $2 \cdot 52$ & $2 \cdot 17$ & $2 \cdot 01$ & $1 \cdot 89$ & 1.67 & $-33 \cdot 7$ \\
\hline $\begin{array}{l}45-54 \\
55-64 \\
65-74 \\
75 \text { and over } \\
\end{array}$ & $\begin{array}{l}2 \cdot 14 \\
3 \cdot 04 \\
2 \cdot 34 \\
2 \cdot 51\end{array}$ & $\begin{array}{l}1 \cdot 98 \\
2 \cdot 02 \\
2 \cdot 73 \\
2 \cdot 49\end{array}$ & $\begin{array}{l}1 \cdot 86 \\
1 \cdot 90 \\
2 \cdot 25 \\
2 \cdot 41\end{array}$ & $\begin{array}{l}1 \cdot 54 \\
1 \cdot 82 \\
2 \cdot 16 \\
2 \cdot 46\end{array}$ & $\begin{array}{l}1 \cdot 50 \\
1 \cdot 58 \\
1 \cdot 67 \\
2 \cdot 29\end{array}$ & $\begin{array}{l}-29 \cdot 9 \\
-48 \cdot 0 \\
-28 \cdot 6 \\
-8 \cdot 8\end{array}$ \\
\hline $\begin{array}{l}\text { Bronchitis } \\
\text { All ages (rates standardized) }\end{array}$ & $2 \cdot 36$ & $2 \cdot 22$ & $2 \cdot 02$ & $1 \cdot 75$ & $1 \cdot 68$ & $-28 \cdot 8$ \\
\hline $\begin{array}{l}45-54 \\
55-64 \\
65-74 \\
75 \text { and over }\end{array}$ & $\begin{array}{l}3 \cdot 25 \\
2 \cdot 61 \\
2 \cdot 63 \\
1 \cdot 73\end{array}$ & $\begin{array}{l}2 \cdot 99 \\
2 \cdot 42 \\
2 \cdot 37 \\
1 \cdot 71\end{array}$ & $\begin{array}{l}1 \cdot 97 \\
2 \cdot 08 \\
2 \cdot 34 \\
1 \cdot 88\end{array}$ & $\begin{array}{l}1 \cdot 64 \\
1.65 \\
1 \cdot 79 \\
1 \cdot 88\end{array}$ & $\begin{array}{l}1 \cdot 53 \\
1 \cdot 76 \\
1 \cdot 64 \\
1 \cdot 74\end{array}$ & $\begin{array}{l}-52.9 \\
-36.4 \\
-37.6 \\
+0.6\end{array}$ \\
\hline
\end{tabular}


considered, viz., 45-54 (53\%), and the next two age groups show similar reductions $(36 \%$ and $38 \%$ respectively). At 75 and over there is no change in the ratio. There is a similar tendency for the maximum difference between the cities and rural areas to shift from younger to older age groups, although the figures are less consistent than for lung cancer. Between 1951 and 1956 the highest ratio is in the 45-54 age group. In 1957-59 it is in the 65-74 age group and in 1960-62 in those dying at 75 and over. In 1963-65 there is little difference between the older age groups.

In general it seems that there is a tendency for rates in the cities and rural areas to be drawing closer together over this period. Although the rates for all ages rise in parallel (Figs 1 and 2), those in the rural areas rise more, proportionately, than do those in the cities. For lung cancer this affects particularly the 55-64 age group (Fig. 3) and for bronchitis the 45-54 age group (Fig. 4).

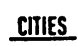

LANOWARO AREAS

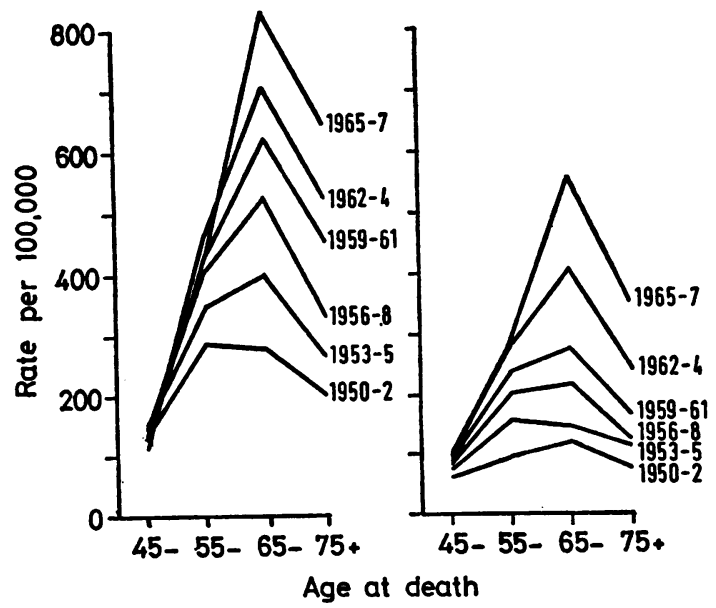

FIg. 5.-Age-specific death rates for lung cancer in males in Scotland $1950-67$, in cities and landward areas, three-year averages.

Figure 5 shows the average age-specific death rates over three-year periods for male lung cancer in cities and rural areas from 1950 to 1967 . Unfortunately no data are available for periods before 1950. In the cities the peak age-specific rate in 195052 occurred in the 55-64 age group. In subsequent years it shifted to the 65-74 age group and remained there. In the rural areas the peak rate in 1950-52 was in the 65-74 age group. A transitory shift back to 55-64 occurred in 1953-55 and then returned to the 65-74 age group where it has remained. The possible significance of these findings will be dealt with in the discussion.

\section{Discussion}

The results indicate that there has been an increasing mortality from lung cancer and bronchitis in Scottish males during the last 15 years in cities and rural areas. These rates have risen in parallel so that the highest proportional changes are seen in the rural areas.

In the 45-54 age group a slightly falling death rate in both lung cancer and bronchitis in cities contrasts with a rising rate in the rural areas. These trends, as indicated by changes in the cities/rural areas ratio, are consistent throughout the period under consideration (Table II) and their significance must be discussed. Several factors could be involved in a decrease of the urban/rural ratio in these two diseases which have certain aetiological factors in common.

Urban and rural rates could approximate owing to an increased mobility of the population. In general the fitter and more active members of a population group are those most likely to move, thus affecting adversely the rates in the residual population. Precise figures on population movements are not available, and estimated figures do not distinguish between internal migration within Scotland and migration to England and Wales and overseas. The greatest loss of population occurs in the sparsely populated areas of the north, and the Border counties, but there is also a loss from central parts of Glasgow to new towns and developing areas. The net effect of such movements on mortality is unlikely to be high but it is conceivable that they could have had some effect on the fall of mortality in the 45-54 age group in the cities. It seems unlikely that they could account for the rise in the rural areas.

Changes in the level of atmospheric pollution have occurred during the period under consideration. Pollution from smoke is known to have decreased considerably in Glasgow and Dundee where measurements have been carried out for a number of years. In the other cities measurements cover a shorter time and are incomplete, but such as they are they indicate that with the more economic use of coal and the switch to other forms of industrial energy, there is a general trend towards a decrease in atmospheric pollution from smoke. Some 'rural' areas may have become more 'urban' with the setting up of new industries and associated residential areas, but these features are recent and are unlikely to have operated long enough as yet to have produced an effect on mortality.

There could be differences in diagnosis and treatment in urban and rural areas. A patient suspected of having lung cancer is likely to be treated at some stage in hospital. Discharge rates for lung cancer 
from Scottish hospitals from 1961 to 1964 inclusive are 96 per 100,000 for cities and large burghs and 72 for the remaining county areas (Scottish Hospitals In-patient Survey 1961-64). Comparing these rates with certified deaths from lung cancer there is a ratio of 1.5 in the large towns and 1.9 in the remaining county areas. This does not suggest that there is any significant failure to diagnose and treat lung cancer outside the large towns. The national survey of the prevalence of chronic bronchitis undertaken by the College of General Practitioners (1961) showed that in rural areas general practitioners accepted less severe symptoms for diagnosing the syndrome 'chronic bronchitis' than their colleagues in the towns. It therefore seems that they would not be less likely than town practitioners to diagnose bronchitis as a cause of death. Hospital discharge rates for bronchitis vary enormously in different parts of the country and correlate poorly with the recorded mortality rates. They cannot therefore be used as an indication of prevalence.

Finally, differences in smoking habits must be considered. The Tobacco Research Council's surveys (Todd, 1966) show that there are now more smokers in the towns than in the rural areas, and that smokers in towns consume more cigarettes. These differences are slight at the present time but if they were greater in the past they could account for at least some of the findings in this study.

In a serial study of male lung cancer deaths in England and Wales between 1901 and 1956, Waller (1959) demonstrated that before 1926 the peak agespecific mortality rate occurred between 65 and 69 years. Subsequently the peak shifted back to the 60-64 age group and later moved forward again to the 65-69 group. He thought this temporary shift backwards indicated a new factor which first exerted an increasing influence on the lung cancer mortality of younger men and then a similar effect on older people. He gave reasons for considering that this factor could be cigarette smoking, and produced some evidence that London was affected in this way before 'other urban' areas, and still more before rural areas, which suggested earlier cigarette smoking in the larger towns. In Scotland the figures presented by Smith (1964) for the country as a whole indicate that a shift in the peak rate to an earlier age group occurred about 1939, which is consistent with a later spread of cigarette smoking in Scotland than in England and Wales. A comparative study of male/ female ratios (Crofton and Crofton, 1963) also suggests a later development of cigarette smoking in Scotland. The data presented in Fig. 5 for cities and rural areas in Scotland show a shift in the peak mortality in the cities from 55-64 in 1950-52 to
65-74 in 1953-55. In the rural areas there is a temporary shift back from 65-74 to 55-64 at this time, and a subsequent shift forward again to 65-74. One would hesitate to lay too much stress on these figures which, unfortunately, cannot be carried further back but they are similar to those demonstrated by Waller for London and rural areas in England and Wales about 15 years earlier.

Smith (1964) showed that in Scotland since 1953 the male lung cancer rates under the age of 50 were steady. He considered that this was a true phenomenon and possibly due to a 'saturation' level having been reached in these younger men who could be regarded as those most sensitive to the carcinogenic properties of cigarette smoke. These men dying in 1953 probably began smoking in 1920-25 at a time when, in the towns, most new smokers would be smoking cigarettes rather than pipes (which are, of course, less liable to lead to later lung cancer). In the rural areas at that time a smaller proportion would probably have taken up cigarette smoking and more would have taken up pipe smoking. Later there would be little scope for a further increase in new cigarette smokers in the cities, but a possibility of considerable further recruitment in rural areas. This may account for still rising rural mortality rate for lung cancer in the 45-54 age group, a rise which is no longer seen in the cities or, in this age group, in the national figures:

The latest surveys from the Tobacco Research Council (Todd, 1966) indicate that, at present, there is more cigarette smoking in Scotland than in England and Wales. The effect of this is already evident in the higher total mortality rate for lung cancer in Scotland which has occurred in spite of the probable shorter duration of cigarette smoking. Part of the increase in Scottish rates for bronchitis may also be attributable to increased cigarette smoking. The fact that this is occurring in rural areas where atmospheric pollution is so much lower than in the cities, and that younger men in rural areas are showing an increasing death rate from bronchitis which is not shown by the younger men (45-54) in the cities, suggests that in the aetiology of chronic bronchitis cigarette smoking may be playing a larger part, compared with atmospheric pollution, than it has in the past.

\section{SUMmaRY}

Standardized mortality rates and age-specific death rates for lung cancer and bronchitis in Scottish males have been calculated for cities and rural areas from 1951 to 1965 (Figs 1 to 4).

In both diseases over this period there has been an increase in the standardized rates and in every agespecific rate, except for those dying between 45 and 
54 in the cities, where it has fallen slightly. The rate of increase is proportionately higher in the rural areas (Table I).

In consequence at each age of death there has been a fall in the ratio between death rates in cities and those in rural areas. This has been greatest for lung cancer in the 55-64 age group and for bronchitis in the 45-54 age group (Table II).

In 1951-53 the greatest difference between the rates in cities and rural areas was in the 55-64 age group. This has subsequently shifted to later age groups. The change is seen in both diseases but is most consistent in lung cancer (Table II).

Population movements, and changes in atmospheric pollution and differences in diagnosis and treatment, may play some part in the changing relationships between cities and rural areas, but it is not thought likely to be a major one.

A comparison of the present findings with other studies suggests that a later beginning of cigarette smoking in rural areas with a subsequent marked increase could account for many of the changes observed.

It is possible that we are now witnessing a change in the relative contributions of atmospheric pollution and cigarette smoking in the aetiology of chronic bronchitis, with the latter becoming more important as atmospheric pollution decreases.

This work was supported by a grant from the Chest and Heart Association.
I am indebted to Dr. M. A. Heasman and to Mr. W. Robertson of the Statistical Department of the Scottish Home and Health Department for unpublished data from the Scottish Hospitals Inpatient Survey.

\section{REFERENCES}

Buck, S. F., and Brown, D. A. (1964). Tobacco Research Council. Mortality from Lung Cancer and Bronchitis in relation to Smoke and Sulphur Dioxide Concentration, Population Density and Social Index. Research Paper No. 7, London.

College of General Practimoners (1961). Chronic bronchitis in Great Britain. A national survey carried out by the respiratory diseases study group of the College of General Practitioners. Brit. med. J., 2, 973.

Crofton, E. C., and Crofton J. W. (1963). Influence of smoking on mortality from various diseases in Scotland and in England and Wales. An analysis by cohorts. Brit. med. J., 2, 1161.

Registrar General for Scotland. Annual Reports 1950 to 1965. H.M.S.O., Edinburgh.

ScotTish Hospitals IN-PATIENT SURVEY 1961 to 1964.

Scottish Home and Health Department. Unpublished data.

SMITH, A. (1964). Supplement. Trends in mortality from respiratory disease, 1929-1963. Annual Report of the Registrar General for Scotland 1963, No. 109, p. 63.

SPRINGETT, V. H. (1966). The beginning of the end of the increase in mortality from carcinoma of the lung. Thorax, 21, 132.

ToDD, G. F. (1966). Tobacco Research Council. Research Paper No. 1, 4th ed., London. Statistics of Smoking in the United Kingdom.

WALLER, R. E. (1959). Air pollution as an aetiological factor in lung cancer. Acta Un. int. Cancr. 15, 437. 